\title{
EL RETO DE LA PLANIFICACIÓN ESTRATÉGICA
}

\author{
Eliana Solano Rojas*
}

La planificación estratégica bien entendida y desarrollada con el propósito de crear valor, orientar los esfuerzos hacia objetivos corporativos y plantear en forma organizada las tareas a realizar, es uno de los procesos más importantes de una organización, podríamos afirmar que contando con una planificación estratégica efectiva, las instituciones logran mejores resultados. Sin embargo, planear no resulta nada sencillo en condiciones como las nuestras: complejos conflictos sociales, incertidumbre económica asociada con riesgos propios del país, constantes cambios en la normatividad legal vigente, mercados volátiles y lo que resulta muchas veces más difícil de afrontar: débil cultura de planificación estratégica. Según estudios recientes los colombianos no tenemos cultura de planeación y preferimos afrontar el futuro de manera espontánea y actuar en el momento que se requiera, es decir sentimos de alguna manera más empatía con la solución de problemas del día a día que con el desarrollo de tareas planificadas.

Esta complejidad y relevancia del proceso de planificación estratégica obliga a los máximos órganos de gobierno de las instituciones a tomar decisiones sustanciales, como destinar recursos para la contratación dé personal experto en el área de forma permanente y destinar parte del tiempo (siendo este uno de los recursos más valiosos) de todos sus colaboradores a construir y desarrollar los planes estratégicos. Esta destinación de recursos demuestra la existencia del ingrediente principal para el desarrollo de la planeación estratégica: compromiso de la dirección.

\footnotetext{
* Asesora de Planeación y Gestión de Proyectos. Fundación Universitaria de Ciencias de Salud. Bogotá DC, Colombia.
}

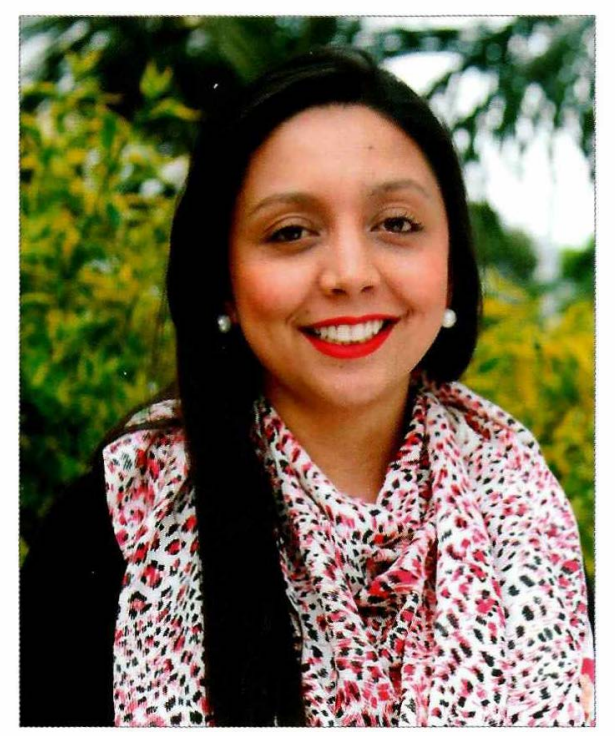

Una vez se cuenta con el ingrediente principal, viene la segunda decisión más importante del proceso de planificación: la metodología que se utilizará para construir y hacer seguimiento del plan. Y es que, aunque existan en la literatura modelos generales de construcción de planes estratégicos, esos modelos deben estar ajustados a la realidad institucional, en donde la cultura juega el rol más importante. Uno de los errores más frecuentes e impactantes es pensar que la metodología aplicada en una institución pueda ser replicada en otra con los mismos resultados, riesgo que se asume cuando las organizaciones deciden contratar firmas de asesoría metodológica (que no conocen la cultura), sin contar con personal experto que lidere el proceso al interior de estas.

El diseño metodológico para la construcción de planes, requiere inexorablemente la identificación de variables institucionales claves como el sector, la disponibilidad de recursos y lo más importante, la cultura 
organizacional. Bajo el estado de estas variables, la alta dirección decidirá con qué tipo de capital humano contará para definir la metodología a implementarse (asesores internos, asesores externos metodológicos o temáticos). Siempre será importante en el momento de tomar esta decisión, tener en cuenta que la trascendencia del proceso requerirá de capital humano interno (con formación y competencias en planificación estratégica) que soporte su desarrollo, pues es muy común encontrar organizaciones en las que asesores que no conocen la realidad y cultura, al finalizar el contrato de asesoría entregan como producto final un plan estratégico que los miembros de la organización no comprenden ni saben cómo gestionar. En todo caso, independiente de las particularidades que aborda cada organización en la metodología para construir el plan, esta debe seguir unos parámetros generales como son la participación de la alta dirección y los colaboradores en su construcción, el diseño de herramientas de fácil acceso y entendimiento y la disponibilidad de información interna y externa a la organización a lo largo de todo el proceso.

Definida y aplicada la metodología para la construcción de planes, nos encontramos con un nuevo desafío, garantizar su cumplimiento. La asignación de recursos para la implementación de planes es prioritario, dichos recursos incluyen el capital humano que hará seguimiento y acompañamiento al desarrollo de las tareas en la organización. Según un estudio de la universidad de Harvard solo el 10\% de las estrategias que se diseñan son implementadas, esto nos permite entender que la planificación estratégica no es solo el ejercicio de definir un plan, sino que trasciende al establecimiento de procedimientos y mecanismos que propendan por el cumplimiento de los objetivos y las metas. En esta etapa es fundamental el diseño e implementación de herramientas de medición de la gestión y coaching gerencial que permitan familiarizar y comprometer a los colaboradores con lo establecido en los planes estratégicos. Por lo general, las organizaciones han orientado sus esfuerzos y recursos a la construcción del plan, dejando de lado lo que es quizá más importante: hacer realidad lo que se planteó en el Plan. Muchas organizaciones están creando de cara a esta realidad las oficinas de "Seguimiento a la Estrategia" que cumplen funciones con más alcance que la acostumbrada auditoria. Estas oficinas acompañan y verifican paso a paso el desarrollo de la estrategia y su impacto en la institución.

Por último, como resultado de un óptimo proceso de planificación estratégica, debe existir un resultado que responda al reto de medir el impacto del plan. En organizaciones sin ánimo de lucro como la Fundación Universitaria de Ciencias de la Salud, los indicadores que responden a esta necesidad no pueden ser solo financieros, el impacto social institucional debe ser medido y cuantificado de forma tal que los esfuerzos desarrollados den cuenta de una gestión eficiente, con implicaciones en el desarrollo y crecimiento sostenible del entorno y del país.

Así pues, la planificación estratégica se convierte en un instrumento de vital importancia, ya que a través de esta, no solo alineamos esfuerzos y recursos institucionales, sino que también construimos sociedad, que es al final lo que cualquier organización con o sin ánimo de lucro tiene como responsabilidad y obligación en la prestación de sus servicios y desarrollo de sus productos. 